\section{Cincuenta años del Programa de Planificación Familiar en Chile}

\section{Fifty years of the Family Planning Program in Chile}

\section{Sr. Editor:}

En el año 2015 se cumplieron 50 años desde la puesta en marcha de las acciones sanitarias destinadas a implementar formalmente una Política de Planificación Familiar en Chile, en el marco de un país que, a inicios de la década de 1960, tenía una población de 6 millones de habitantes, $60 \%$ de ellos en situación de pobreza. La escolaridad promedio alcanzaba 2 años cursados formalmente y $23 \%$ de la población era analfabeta ${ }^{1}$. La tasa de mortalidad materna correspondía a 118 muertes maternas por 100 mil nacidos vivos, la tasa global de fecundidad alcanzaba a 5,4 hijos promedio por mujer y la cobertura de la atención profesional del parto era de $66,9 \%$. El aborto constituía la principal preocupación sanitaria del país, por ser la primera causa de muerte en la población femenina en edad fértil, afectando principalmente a mujeres casadas, entre los 20 y 34 años de edad, que tenían hasta 3 hijos vivos y pertenecían a grupos socioeconómicos de ingresos bajos. La tasa de abortos inducidos se estimaba en 107 por 100.000 nacidos vivos y más de la mitad de la disponibilidad de los bancos de sangre se utilizaba en complicaciones derivadas de abortos sépticos ${ }^{2}$.

Entre los esfuerzos realizados en Chile antes del inicio de la política, destacó la tarea de los Hospitales José Joaquín Aguirre y Barros Luco, cuyos equipos de salud entregaban educación sexual y divulgaban estrategias de anticoncepción entre sus usuarias, a fin de aportar en la superación de prácticas femeninas de prevención e interrupción del embarazo afectadas por la desinformación y la “justificación mágica”. En el Hospital Barros Luco se desarrolló una propuesta de anillo anticonceptivo, por parte de los médicos Hernán Sanhueza y Jaime Zipper, que sirvió de base para avances posteriores en la materia. En forma especial, debe reconocerse el aporte del Dr. Benjamín Viel, cuya permanente investigación en torno a la salud pública, el crecimiento demográfico y la planificación familiar, aportaron sólidos fundamentos y antecedentes diagnósticos a la urgente tarea sanitaria que debía desarrollarse en estas materias.
En 1962 visitó Chile la Sra. Ofelia Mendoza, Trabajadora Social, Master en Sociología y directora técnica de la International Planned Parenthood Federation (IPPF), promoviendo una discusión pública sobre la necesidad de adoptar medidas sanitarias para la regulación de la natalidad. Este debate fue acogido por el Dr. Gustavo Fricke, Director General de Salud de la época, quien convocó a equipos profesionales de la Universidad de Chile y la Universidad Católica de Chile, para crear un Comité Asesor en la materia, destinado a organizar la prevención del aborto inducido. Su primera presidenta fue la Dra. Luisa Pfau y sus objetivos buscaron reducir las tasas de natalidad, la mortalidad materna y la letalidad por aborto. En 1963, tras la participación en la VII Conferencia Internacional de IPPF, el delegado chileno Dr. Onofre Avendaño anunció la creación del Comité Chileno de Protección de la Familia y la llegada al mercado de métodos anticonceptivos: gestágenos y dispositivos intrauterinos, considerados más eficaces para el control de la natalidad. En 1964 funcionaban a lo largo del país 26 centros de planificación familiar, que contaban con el apoyo institucional del Servicio Nacional de Salud. Un año más tarde, el gobierno de don Eduardo Frei Montalva otorgó personalidad jurídica al Comité, que pasó a llamarse Asociación Chilena de Protección de la Familia (APROFA) 3 .

En 1965, el Dr. Francisco Mardones Restat asumió como Director del Servicio Nacional de Salud, declarando explícitamente la responsabilidad del organismo frente a los problemas del aborto inducido y el crecimiento de la población, dando inicio a acciones de regulación de fertilidad que contaron con pleno respaldo del Ministerio de Salud y de organismos técnicos y académicos asesores, impulsando una política pública que fue definida como Paternidad Responsable. Los equipos de salud desarrollaron a lo largo del país permanentes actividades educativas para promover el ingreso informado a los programas de planificación familiar que se iniciaban, y para orientar a la población respecto de la efectividad de las medidas adoptadas y sus implicancias en la calidad de la salud de la mujer. Esta política fue implementada en la población femenina nacional con fertilidad probada, que a la fecha había sido formada en el ejercicio de roles sexuales tradicionales con fuerte raigambre patriarcal, cuyo proyecto de vida desde su calidad de sujeto 
sexualmente pasivo definía a la maternidad como una realización vital central. La implementación de la política permitió el tránsito desde una construcción cultural de maternidad que no poseía dominio sobre los eventos reproductivos, hacia el ejercicio de mayores grados de decisión en la propia vida reproductiva a partir del derecho de decidir el número de hijos que se deseaba procrear y el espaciamiento entre nacimientos. Todo ello, facilitado por una oferta de servicios sanitarios oportunos, asistencia anticonceptiva adecuada y educación sexual complementaria, respaldada por los avances científicos disponibles en la materia, permitiendo desincentivar las antiguas y riesgosas prácticas abortivas vigentes en la época ${ }^{4}$.

Actualmente, a cincuenta años del inicio de su implementación, las estadísticas nacionales reflejan el impacto de las medidas de planificación familiar. La tasa de mortalidad materna ha disminuido a 20 muertes maternas por 100 mil nacidos vivos en el año 2000, la tasa global de fecundidad ha descendido a 1,9 hijos promedio por mujer en el año 2010 y la atención profesional del parto alcanza a 99,8\%. La fecundidad del país descendió en $65 \%$ en cinco décadas y no se aprecian factores internos que alteren la tendencia en el futuro. Actualmente, el aborto posee un peso marginal en la tasa global de mortalidad materna, con 0,8 por 100.000 nacidos vivos. En forma complementaria, debe señalarse que en 1960 3,4\% de las mujeres tenía estudios universitarios, cifra que sube en la actualidad a 25\%. Asimismo, en 1960 las mujeres representaban $21 \%$ de la fuerza laboral chilena, incrementándose a 46,6\% en el año 20105. La tarea de planificación familiar iniciada en la urgencia se ha transformado en la actualidad en la piedra angular para el ejercicio pleno de los derechos reproductivos de la población nacional.

\author{
Patricia Castañeda Meneses ${ }^{1, a}$, \\ Ana María Salamé Coulon ${ }^{2, b}$ \\ ${ }^{1}$ Escuela de Trabajo Social. Universidad de \\ Valparaíso. Valparaiso, Chile. \\ ${ }^{2}$ Departamento de Trabajo Social. Universidad \\ de La Frontera. Temuco, Chile.
}

${ }^{a}$ Trabajadora Social. Doctora en Ciencias de la Educación. Universidad de Barcelona, España. ${ }^{b}$ Trabajadora Social. Doctora en Ciencias de la Educación. Universidad de Barcelona, España.

\section{Referencias}

1. Goic A. El Sistema de Salud de Chile: una tarea pendiente. Rev Med Chile 2015; 143 (6): 774-86. Disponible en http://www.scielo.cl/scielo.php?script=sci_arttext\&pid=S0034-98872015000600011\&lng=es\&tlng=es. 10.4067/S0034-98872015000600011 [Consultado el 25 de septiembre de 2015].

2. Szot J. Reseña de la salud pública materno-infantil chilena en los últimos 40 años: 1960-2000. Rev Chil Obstet Ginecol 2002; 67 (2): 129-35. Disponible en: $<$ http://www.scielo.cl/scielo.php?script=sci_arttext\&pid $=$ S0717-75262002000200009\&lng $=$ es\&nrm $=$ iso $>$. ISSN 0717-7526. http://dx.doi.org/10.4067/S071775262002000200009 [Consultado el 18 de enero de 2015].

3. Jiles X, Rojas C. De la miel a los implantes. Historia de las Políticas de Regulación de la Fecundidad en Chile. Corporación de Salud y Políticas Sociales CORSAPS. Santiago de Chile, 1992 pp. 104-44.

4. Castañeda P, Salamé AM. 50 años de planificación familiar en Chile, 1965-2015: Experiencias de las primeras generaciones de mujeres urbanas usuarias del programa. Rev Chil Obstet Ginecol 2015; 80 (3): 208-14. Disponible en http://www.scielo.cl/scielo.php?script=sci_arttext\&pid=S0717-75262015000300002\&lng=es\&tlng=es. 10.4067/S0717-75262015000300002 [Consultado el 25 de septiembre de 2015].

5. Instituto Nacional de Estadísticas. Anuario de Estadísticas Vitales. Informe Anual 2012. INE. Santiago de Chile 2012 pp. 15-38. 